\title{
Experimental approach for exploring the characteristics of convective vortices as an alternative "green" energy concept
}

\author{
S. Nizetic, F. G. Cabo \& L. Ticinovic \\ Department of Thermodynamics and Heat Engines, Faculty of Electrical \\ Engineering, Mechanical Engineering and Naval Architecture, \\ University of Split, Croatia
}

\begin{abstract}
This paper addresses the specific construction and design of a convective vortex simulation chamber and also elaborates on the alternative energy concepts with convective vortices. Convective vortices could be used as heat engines for electricity production. Electricity could be produced without carbon dioxide emissions if solar energy were used as the heat input into the system. The main part of the energy concept is the gravitational vortex (convective vortices). Research of the behaviour of convective vortices is crucial in order to define specific circumstances for the genesis and maintenance of convective vortices. Hence, a simulation chamber is established to explore some important convective vortex characteristics and to validate some proposed theoretical assumptions. From that point this paper elaborates in detail a specific experimental approach as the basis for future research regarding this specific topic of research - convective vortices as heat engines.

Keywords: convective vortices, simulation chamber, alternative energy concept, heat engines.
\end{abstract}

\section{Introduction}

The idea of the possible utilisation of convective vortices for energy utilisation was first proposed by Michaud $[1,2]$. The second proposed concept of a modified solar chimney power plant, in which a solid chimney (the solar chimney power plant concept described in $[3,4]$ ) is replaced with a gravitational vortex, is elaborated in [5] and further developed in [6]. A literature review of 
the different concepts involving convective vortex utilisation and of previous research on this topic can be found in [7]. The main component of the previously mentioned concepts $[1,2,5]$ is convective vortices. This type of system can be understood as a heat engine. Figure 1 briefly explains the proposed approach. It is obvious that heat input is key. Heat could be obtained from industrial waste heat or even solar energy (in that case, carbon-free electricity production could be ensured). The debate is focused on the following two questions: Can we produce convective vortices by artificial means? Can we simultaneously extract useful mechanical (shaft) work and produce electricity with, for example, a turbine and generator assembly? Nature proves that it is possible to establish convective vortices in the surroundings (e.g., dust devils, waterspouts, tornadoes, etc.), and from this observation, it is obvious that the solution is to perceive and detect specific natural mechanisms.

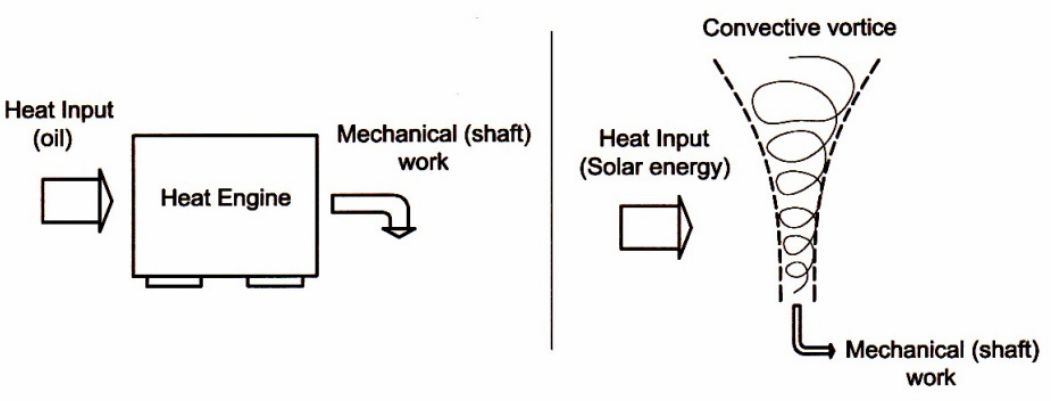

Figure 1: $\quad$ Convective vortices as heat engines [7].

It is important to conduct research on the nature of convective vortices and to study their characteristics because gravitational vortices will be an important part of future energy production systems. For this purpose, a vortex simulation chamber was developed according to the suggestions from Grazulis [8]. Certain specific parts that were important for the specific research tasks were modified.

Hence, the objective of this paper is to describe the specific construction details of the simulation chamber and to define the main goals of future research.

\section{The idea of the energy transformation}

As previously mentioned, there is a similarity between the heat engine concept and convective vortex energy utilisation concepts. Both of the proposed concepts produce useful mechanical (shaft) work (Fig. 1), but in the case of the convective vortices, the main question is how much of the heat input delivered to the system could be used for electricity production. It is obvious and expected that the main quantity of the delivered heat will be used for the maintenance of the convective vortices in the surroundings. Only a small portion of the heat input will be available in the form of useful mechanical work (but no matter how small this portion is, in terms of the magnitude, the energy potential is huge and can be 
measured in TW). To answer the previous question, theoretical research is important, and for this purpose, a heat engine framework is often used. Research in this specific area is still in progress, but some interesting proposed theories about general convective characteristics that have been compared with specific and available ground observation data can be found in [5-7] and [8-13]. Experimental attempts to produce artificial convective vortices can be found in $[1,2]$ and $[14-16]$.

\section{Experimental approach}

\subsection{Design of the vortex simulation chamber}

According to the suggestions from T. P. Grazulis, the director of the Tornado Project [8], a tornado chamber was built and placed into service. Slight chamber modifications have been made, and new features have been added to provide research flexibility. The simulation chamber is divided into three main parts (Fig. 2). The lower portion of the chamber is a double box. It consists of two hollow boxes of different sizes in which the smaller box is positioned in the centre of the larger box. On the lateral sides of the larger box, two fans have been placed to ensure a pressure increase within the box. On the larger fan, a vane is placed to regulate the flow and to establish a pressure variation. The smaller box is equipped with an ultrasonic steamer to make visible vortices. On the top of the smaller box, a hole is drilled to direct the steam into the middle portion of the chamber. Furthermore, eight plastic tubes are placed in a circular pattern around the hole drilled in the large box. Plastic tubes are drilled on the inner side and positioned in the larger box (nineteen small holes have been drilled in each tube).

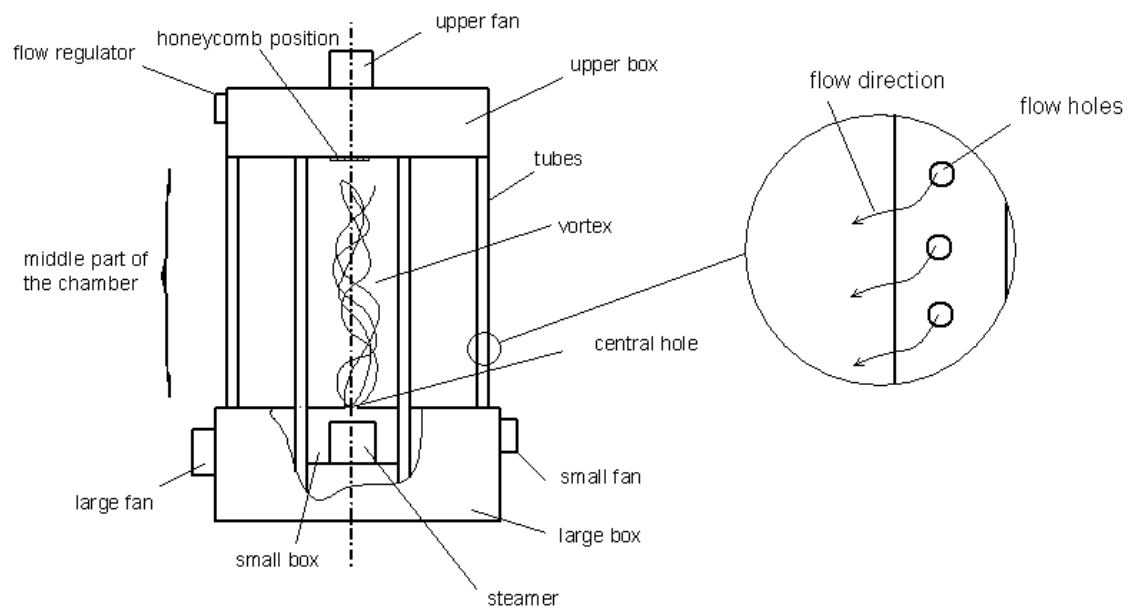

Figure 2: $\quad$ Simplified overview of the convective vortex simulation chamber design. 
The tubes are positioned in such a way that the air stream is tangential to the convective vortices. The top portion of the chamber is also a box, but it has a circular hole in its centre into which an axial fan is placed. The installed power of the fan is $180 \mathrm{~W}$, and it has a voltage regulator with which different flow values can be achieved. A honeycomb component has been placed at the fan entrance to prevent backflow from the ventilator and to ensure linear flow into the ventilator (hence, the ventilator is not affecting the way in which natural vortices rotate).

\subsection{Measuring equipment}

The measuring equipment consists of differential pressure sensors with an accuracy of $0.2 \%$, a measurement range of $\pm 500 \mathrm{~Pa}$ and the possibility of data logging with a PC suite. Relative humidity and temperature data loggers with 8 channels, a PC suite and software are also used. To measure the temperature and the air velocity, two hot-wire thermo-anemometers (with a measurement range from 0.15 to $30 \mathrm{~m} / \mathrm{s}$, accuracy: $\pm 3 \%$ ) and two air flow measurement devices with a measurement range from 0 to $99999 \mathrm{~m}^{3} / \mathrm{h}$ and an accuracy of $\pm 3 \%$ are used. There are plans to apply Laser Doppler Velocimeter (LDV), also known as Laser Doppler Anemometer (LDA), in the future to measure the flow speed of the transparent or semi-transparent steam in the vortex. This LDA will be specially designed for this purpose. Different geometry of convective vortices can be formed by the experimental equipment, which is useful to see how specific flow parameters are affecting the shape and stability of the convective vortices. Regarding the previous, Fig. 3 represents the established convective vortex in the specific developed geometry and in general it demonstrates the experimental equipment in the working regime.

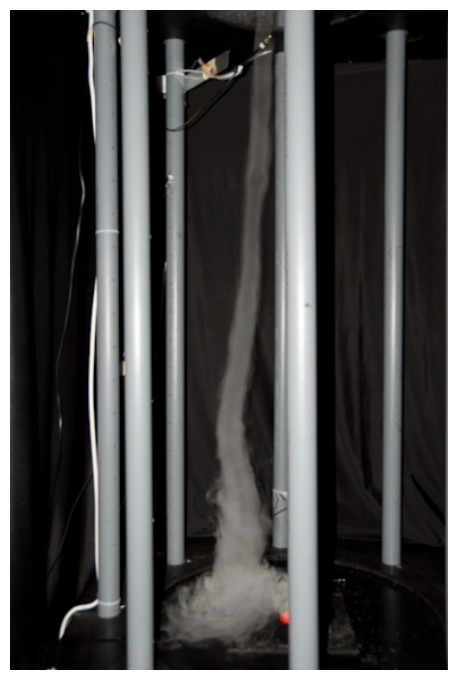

Figure 3: Example of the established convective vortex. 


\section{Future research work}

Future research will be focused on the investigation of the convective vortex characteristics and also on the validation of some important theoretical conclusions and assumptions. The air temperature and the impact of humidity on the structure and general behaviour of convective vortices will also be considered. However, the most important contribution will be the knowledge about the pressure and velocity distribution in the convective vortices under different conditions. Thus, the LDA device is crucial, but unfortunately, it is quite expensive because it must be specially designed for the considered purpose. At the moment, numerical modelling of convective vortices is in progress and also CFD analysis will be performed. From that aspect, a developed experimental simulation chamber will be useful to derive important conclusions regarding the heat to work efficiency of convective vortices as heat engines.

\section{Conclusions}

Research into alternative energy concepts is important because of the unpredictability of the future due to factors such as the variability in the prices of fossil fuels and limited fossil fuel resources. Therefore, the key is to prepare techno-economically viable solutions that would temper our dependence on fossil fuel. In this paper, one type of this solution that involves convective vortices as the main component is briefly elaborated. Theoretical research is necessary, but experiments are also crucial. From that perspective, the specific details of the construction of a simulation chamber (based on to the suggestions of T. P. Grazulis, but slightly modified) are elaborated in this paper, and specific construction details are also introduced. Finally, it can be concluded that this concept is viable, and continuous research on this concept should be conducted.

\section{Acknowledgements}

The authors would like to thank the Croatian Ministry of Science, Education and Sports (research project 023-0231751-3011) and the Carlsberg Croatia d.o.o. for funding this project.

\section{References}

[1] Michaud, L.M., Proposal for the use of a controlled Tornado-like Vortex to Capture the Mechanical Energy Produced in the Atmosphere from Solar Energy, Bulletin American Meteorological Society, 56(5), pp. 530$534,1975$.

[2] Website:http://www.vortexengine.ca/,

[3] Sclaich, J. The Solar Chimney, Edition Axel Menges, Stuttgart, pp. 12-33, 1995. 
[4] Nizetic, S., Ninic N. and Klarin B., Analysis and feasibility of implementing solar chimney power plants in the Mediterranean region. Energy, 33, pp. 1680-1690, 2008.

[5] Ninic, N. and Nizetic, S., Elementary theory of stationary vortex columns for solar chimney power plants. Solar Energy, 83(4), pp. 462-476, 2009.

[6] Nizetic, S., An atmospheric gravitational vortex as a flow object: improvement of the three-layer model. Geofizika, 27 (1), pp. 1-20, 2010.

[7] Nizetic, S., Technical utilisation of convective vortices for carbon-free electricity production: A review. Energy, 36, pp. 1236-1242, 2011.

[8] Website:http://www.tornadoproject.com/tornproj/tornproj.htm.

[9] Renno, N.O., Burkett, M.L. and Larkin, M.P., A simple theory for dust devils. Journal of Atmospheric Sciences, 55, pp. 3211-3252, 1998.

[10] Renno, N.O., A thermodynamically general theory for convective vortices. [10] Tellus, 60A, pp. 688-699, 2008.

[11] Renno, N.O. and Bluestein, H.B., A simple theory for waterspouts, $J$. Atmos. Sci., 58, pp. 927-932, 2001.

[12] Ninic, N., Z. Juricand Nizetic, S., Thermodynamical aspect of definitions "CAPE" and "TCAPE". Geofizika, 23 (2),pp. 143-154,2006.

[13] Michaud, L.M., Vortex process for capturing mechanical energy during upward heat-convection in the atmosphere. Applied Energy.62 (4), pp. 241251.1999.

[14] Snow, T.J., Considerations in exploring laboratory tornado like vortices with a laser Doppler velocimeter. Journal of Atmospheric and ocean technology. 14, pp. 1412-426, 1996.

[15] Church, C.R., Snow, J.T. and Dessens, J., Intense atmospheric vortices associated with a $1000 \mathrm{MW}$ fire. Bulletin American Meteorological Society, 61, pp. 682-694.1980.

[16] Fred, L.H.J., Partha. P.S., and William, A.G., Design, construction and performance of a large tornado simulator for wind engineering applications. Engineering Structures, 30, pp. 1146-1159.2008. 